\title{
Barbarea vulgaris Glucosinolate Phenotypes Differentially Affect Performance and Preference of Two Different Species of Lepidopteran Herbivores
}

\author{
Hanneke van Leur • Louise E. M. Vet • \\ Wim H. van der Putten • Nicole M. van Dam
}

Received: 19 October 2007 /Revised: 5 December 2007 / Accepted: 21 December 2007 /Published online: 23 January 2008

(C) The Author(s) 2007

\begin{abstract}
The composition of secondary metabolites and the nutritional value of a plant both determine herbivore preference and performance. The genetically determined glucosinolate pattern of Barbarea vulgaris can be dominated by either glucobarbarin (BAR-type) or by gluconasturtiin (NAS-type). Because of the structural differences, these glucosinolates may have different effects on herbivores. We compared the two Barbarea chemotypes with regards to the preference and performance of two lepidopteran herbivores, using Mamestra brassicae as a generalist and Pieris rapae as a specialist. The generalist and specialist herbivores did not prefer either chemotype for oviposition. However, larvae of the generalist M. brassicae preferred to feed and performed best on NAS-type plants. On NAS-type plants, $100 \%$ of the $M$. brassicae larvae survived while growing exponentially, whereas on BAR-type plants, M. brassicae larvae showed little growth and a mortality of $37.5 \%$. In contrast to $M$.
\end{abstract}

Electronic supplementary material The online version of this article (doi:10.1007/s10886-007-9424-9) contains supplementary material, which is available to authorized users.

H. van Leur $(\bowtie) \cdot$ L. E. M. Vet • W. H. van der Putten •

N. M. van Dam

Department of Multitrophic Interactions,

Netherlands Institute of Ecology (NIOO-KNAW),

Centre for Terrestrial Ecology,

P.O. Box 40, 6666 ZG Heteren, The Netherlands

e-mail: h.vanleur@nioo.knaw.nl

L. E. M. Vet

Laboratory of Entomology,

Wageningen University and Research Centre,

P.O. Box 8031, 6700 EH Wageningen, The Netherlands

W. H. van der Putten

Laboratory of Nematology,

Wageningen University and Research Centre,

P.O. Box 8123, 6700 ES Wageningen, The Netherlands brassicae, the larval preference and performance of the specialist $P$. rapae was unaffected by plant chemotype. Total levels of glucosinolates, water soluble sugars, and amino acids of $B$. vulgaris could not explain the poor preference and performance of M. brassicae on BAR-type plants. Our results suggest that difference in glucosinolate chemical structure is responsible for the differential effects of the $B$. vulgaris chemotypes on the generalist herbivore.

Keywords Glucosinolates · Oviposition · Performance · Polymorphism - Barbarea vulgaris . Pieris rapae.

Mamestra brassicae $\cdot$ Co-evolution

\section{Introduction}

Glucosinolates and their breakdown products are involved in plant defense against a wide variety of potential plant enemies. They can also serve as feeding and oviposition stimulants for specialist herbivores (Chew 1988; Louda and Mole 1991; Wittstock et al. 2003). The composition of glucosinolates is genetically variable within plant species, and influences the feeding choices of insect herbivores (Kroymann et al. 2001; Lambrix et al. 2001). A heritable glucosinolate polymorphism in Barbarea vulgaris results in two discrete chemotypes (Van Leur et al. 2006). In this study, we investigate the effect of these two chemotypes on the preference and performance of two lepidopterans.

The most common and genetically dominant chemotype of B. vulgaris forms mainly (S)-2-hydroxy-2-phenylethyl glucosinolate (glucobarbarin, BAR-type). Although depending on the presence of cofactors like ESP, $\mathrm{pH}$, or metal ions (Burow et al. 2006), the most likely initial hydrolysis product of glucobarbarin is an isothiocyanate. Due to the 2-hydroxylation of the glucosinolate side chain, 
it spontaneously cyclizes to 5-phenyloxazolidine-2-thione (Kjaer and Gmelin 1957). This glucosinolate breakdown product is known to reduce infection by the soil fungus Plasmodiophora brassicae (Ludwig-Müller et al. 1999). Hardly anything is known about other ecological activities of oxazolidine-2-thiones (Wittstock et al. 2003).

The less abundant and genetically recessive chemotype of $B$. vulgaris contains mainly 2-phenylethyl glucosinolate (gluconasturtiin, NAS-type). 2-Phenylethyl glucosinolate is also present in Arabidopsis thaliana and other Brassicaceae (Reichelt et al. 2002), predominantly in root tissues (Sang et al. 1984). Its most likely breakdown product is 2phenylethyl isothiocyanate. Isothiocyanates are the predominant breakdown products of glucosinolates and are generally toxic to various herbivores (Wittstock et al. 2003). 2Phenylethyl isothiocyanate negatively affects a broad range of phytophages, e.g., nematodes (Potter et al. 1999, 2000; Serra et al. 2002; Lazzeri et al. 2004), snails (Kerfoot et al. 1998), flies, aphids, mites (Lichtenstein et al. 1962), fungi (Sarwar and Kirkegaard 1998), and several generalist and specialist Lepidoptera (Wadleigh and Yu 1988; Borek et al. 1998). Despite counter-adaptations of specialists to reduce or circumvent negative effects of glucosinolates (Ratzka et al. 2002; Wittstock et al. 2003), isothiocyanates can still reduce survival and growth, and increase development time of specialists (Agrawal and Kurashige 2003). In contrast to the oxazolidine-2-thiones formed in BAR-type plants, which can increase the incidence of goiter in mammals, the 2phenylethyl isothiocyanate formed in NAS-type plants has chemopreventive effects against tumorigenesis in mammalian organisms (Canistro et al. 2004).

Based on the specific biological effects of the expected breakdown products of glucobarbarin and gluconasturtiin, we hypothesized that NAS-type and BAR-type B. vulgaris plants have differential effects on insect herbivores. Generally, it is expected that chemical plant defenses are more effective against generalist herbivores than against specialists (Cornell and Hawkins 2003). Therefore, we compared the preference and performance on the two chemotypes of a generalist (Mamestra brassicae) and a specialist (Pieris rapae) herbivore, which are both wellstudied, important crucifer pests (Theunissen et al. 1985; Finch and Kienegger 1997).

M. brassicae is a generalist feeding on plants in 70 species and 22 families, of which Brassicaceae are among the most preferred (Rojas et al. 2000). Even though $M$. brassicae can detect glucosinolates by receptor cells on the sensilla (Wieczorek 1976), and its oviposition is stimulated by damaged cabbage plants (Rojas 1999), no physiological adaptations of this species to glucosinolates have been yet described. The larvae of $P$. rapae, on the other hand, can detoxify glucosinolates by shifting hydrolysis products from isothiocyanates to less toxic nitriles by using the myrosinase directing nitrile-specifier protein (NSP). This enables $P$. rapae to consume foliage that is otherwise well defended (Wittstock et al. 2003, 2004). Female adults of $P$. rapae can detect intact glucosinolates in leaves of Brassicaceae with specialized receptor cells, and are stimulated to lay eggs on glucosinolate containing plants.

We assessed herbivore preference on the level of adult oviposition and larval feeding. Female oviposition preference initially determines the host of the larvae (Akhtar and Isman 2003). As the isothiocyanates from NAS-type plants are expected to be more toxic than the oxazolidine-2thiones produced by BAR-type plants, we expected $M$. brassicae to be repelled by NAS-type plants and to prefer BAR-type plants for oviposition. Oviposition of P. rapae is affected by glucosinolates at the leaf surface (Renwick et al. 1992; Van Loon et al. 1992) and known to be stimulated by glucobarbarin as well as by gluconasturtiin in a dosedependent way (Chew 1988; Huang and Renwick 1994; Huang et al. 1994a, b).

As larvae can eventually leave their initial host (van Dam et al. 2000), we also assessed larval preference. If the B. vulgaris chemotypes differ in toxicity or palatability, we expect to see the largest effect on larval preference and larval performance for the unadapted generalist $M$. brassicae and no or minor effects on the glucosinolate specialist $P$. rapae.

Although we observed no differences in morphology, growth, or germination between the chemotypes (van Leur and van Dam, unpublished results), pleiotropic effects or close linkages could possibly cause other genes and metabolites to be consistently different between the chemotypes. As the nutritional value of plants is important for herbivore performance and preference (Simpson and Simpson 1990; Berenbaum 1995), additionally, we analyzed the sugar content and amino acid level of the tissue on which the herbivores were feeding.

\section{Materials and Methods}

Plant Material B. vulgaris seeds were collected from 10 individual BAR and their nearest neighbor NAS-type maternal plants, which were freely cross pollinated in a natural population of $B$. vulgaris. The population was located in Elderveld, The Netherlands $\left(51.95^{\circ} \mathrm{N} ; 5.87^{\circ} \mathrm{E}\right)$ and consisted of $22 \%$ NAS-type plants (Van Leur et al. 2006). We selected offspring of maternal NAS-type plants "EL44" (68\% BAR-type offspring) and "EL13" (62\% BAR-type offspring). Plants were grown in a glasshouse, at $21^{\circ} \mathrm{C}$ (day) and $16^{\circ} \mathrm{C}$ (night), with $60 \%$ relative humidity and natural daylight supplemented with sodium lamps to maintain the minimum PAR at $225 \mu \mathrm{mol} \mathrm{m}{ }^{-2} \mathrm{~s}^{-1}$ with a photoperiod of 16:8 (L:D). One week after germination on glass beads, seedlings were transplanted to a mixture of 
peat soil (Potgrond 4, Lentse Potgrond BV., Lent, The Netherlands) and 20\% sand. After 2 weeks, the seedlings were transplanted to 1.1-1 pots, watered, and fertilized regularly with half strength Hoagland's nutrient solution with a doubled $\mathrm{KH}_{2} \mathrm{PO}_{4}$ content.

Chemical Analysis For quantification of glucosinolates, soluble sugars, and amino acids, one global extraction was used. In a 2-ml Eppendorf tube, $50.0 \mathrm{mg}$ of lyophilized finely ground plant material were dissolved in $1.0 \mathrm{ml} 70 \%$ $\mathrm{MeOH}$ in water $(v / v)$, vortexed, and immediately boiled for $5 \mathrm{~min}$ to kill the remaining myrosinase activity. Tubes were placed in an ultrasonic bath for $15 \mathrm{~min}$ and centrifuged (10 min 10,000 rpm). The extraction was repeated for the pellet omitting the boiling step. For each sample, both supernatants were combined in a new 2-ml Eppendorf tube and supplemented individually with $70 \% \mathrm{MeOH}$ to attain the average mass $(N=3)$ of a 2-ml Eppendorf tube that

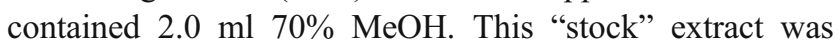
stored at $-20^{\circ} \mathrm{C}$ until further analysis.

Half $(1.0 \mathrm{ml})$ of the stock extract was used for glucosinolate analysis and applied to a DEAE-Sephadex A 25 column (EC 1990), desulfated with arylsulfatase (Sigma, St. Louis, MO, USA) and separated on a reversed phase C-18 column on HPLC with a $\mathrm{CH}_{3} \mathrm{CN}-\mathrm{H}_{2} \mathrm{O}$ gradient as described in van Dam et al. (2004). Glucosinolate analysis was performed with a PDA detector (200-350 nm) with $229 \mathrm{~nm}$ as the integration wavelength. Desulfoglucosinolate peaks were identified by comparison of HPLC retention times and UV spectra with authentic standards isolated from $B$. vulgaris as previously described (Agerbirk et al. 2001), as well as standards kindly provided by M. Reichelt, MPI Chemical Ecology, and a certified rape seed standard (Community Bureau of Reference, Brussels, code BCR-367R). The same response factor was used for glucobarbarin as for gluconasturtiin (Buchner 1987). To calculate glucosinolate concentrations in the plant tissue, the obtained values were multiplied by two and divided by dry mass.

To analyze soluble sugar content, a $10-\mu 1$ aliquot of the stock extract was diluted with $990 \mu \mathrm{l}$ MilliQ water. Soluble sugars were analyzed by injecting $5 \mu \mathrm{l}$ of the diluted extract on Dionex HPLC system, equipped with a Carbopac PA1 column $(2 \times 250 \mathrm{~mm})$ and a Carbopac PA1 guard column $(2 \times 50 \mathrm{~mm}$, Dionex, Sunnyvale, CA, USA). An isocratic gradient mixture of $10 \% 1 \mathrm{M} \mathrm{NaOH}$ and $90 \%$ MilliQ water was used to separate sugars at a flow rate of $0.25 \mathrm{ml} / \mathrm{min}$. Column temperature was kept at $20^{\circ} \mathrm{C}$. A " $10-\mathrm{ppm}$ " reference solution that contained $54.9 \mu \mathrm{M}$ sorbitol and manitol, $29.21 \mu \mathrm{M}$ trehalose, sucrose, and melbiose, and $55.51 \mu \mathrm{M}$ glucose and fructose, was diluted to obtain 7.5, 5 , and $2.5 \mathrm{ppm}$ calibration standards to obtain a reference curve. After every 10 samples, an additional standard was injected to check for deviations of retention times and the calibration curve. To calculate the molar concentration of sugars in the plant tissue, the concentration values were multiplied by 200 and divided by dry mass.

Amino acids were analyzed on a Dionex HPLC system by integrated pulsed amperometric detection. An aliquot of $20 \mu \mathrm{l}$ of the stock extract was diluted with $980 \mu \mathrm{l}$ MilliQ. Of this diluted extract, $25 \mu \mathrm{l}$ were injected, and amino acids were separated with a ternary gradient (see DIONEX application update 152, Method 1, standard AAA gradient; condition 60/2 in Hanko and Rohrer 2004) on a $2 \times 250 \mathrm{~mm} \mathrm{AminoPac}{ }^{(C)}$ PA10 column with a $2 \times 50 \mathrm{~mm}$ AminoPac ${ }^{\complement}$ PA10 Guard column (Dionex, Sunnyvale, CA, USA). Eluents, flow rates, waveform, and working electrode conditions were all as specified under Method 1 in Dionex application update 152 and in Hanko and Rohrer (2004). The Sigma AA-S-18 amino acid standard (Sigma, St Louis, MO, USA) that contained 17 amino acids was supplemented with asparagine, glutamine, and tryptophane $(2.5 \mu \mathrm{mol} / \mathrm{ml}$ each $)$ to obtain a reference sample that contained the 20 most common amino acids. This reference solution was diluted to obtain calibration standard ranging from $1-8 \mu \mathrm{M}$ for each amino acid, except for cysteine, which had a range of $0.5-4 \mu \mathrm{M}$. After every 10 samples, an additional standard was injected to check for deviations of retention times and the calibration curve. To calculate the molar concentration of the amino acids in the plant tissue, the concentration values were multiplied by 200 and divided by dry mass.

To determine the chemotype of each plant, glucosinolates were extracted from the first full grown leaf and analyzed on HPLC as described above. When the peak area of glucobarbarin divided by the peak area of gluconasturtiin was $>10$, the plant was considered a BAR-type. When this ratio was $<0.1$, it was considered a NAS-type.

Oviposition Insects were obtained from the Laboratory of Entomology of Wageningen University the Netherlands. Stock colonies of $P$. rapae and $M$. brassicae were maintained on Brassica oleracea var. gemnifera L., cultivar Cyrus, in a climatized room at $20-22^{\circ} \mathrm{C}, 50-70 \%$ relative humidity, and a photoperiod of 16:8 (L:D). We used ca. 4month-old half-sib plants of family EL44 that were clipped 1 month before use to ensure abundant fresh leaf material. At the start of the experiment, plants were moved from the glasshouse to a climatized room at $21^{\circ} \mathrm{C}$ (day) $16^{\circ} \mathrm{C}$ (night), $60 \%$ relative humidity, illuminated to 200 PAR at plant height (Philips Master TLD 50W/840 HF and $60 \mathrm{~W}$ lights) and a photoperiod of 16:8 (L:D). In the same room, 1- to 3day-old adult insects were held in a mesh cage $(40 \times 45 \times$ $65 \mathrm{~cm}^{3}$ ) provided with sugar solution. Males and females were held together to mate for at least $24 \mathrm{~h}$. Oviposition preference was assessed by introducing individual pairs into one of the 11 oviposition mesh cages $\left(40 \times 45 \times 65 \mathrm{~cm}^{3}\right)$ each containing one BAR-type and one NAS-type plant and 
a source of sugar. Oviposition was checked every day at 10.30 and 15.30 h. M. brassicae oviposition was recorded $24 \mathrm{~h}$ after the first egg up to 7 days after introduction $(N=$ 68). P. rapae oviposition was recorded for at least $5 \mathrm{~h}$ after the first egg and up to a maximum of $24 \mathrm{~h}$ in total $(N=35)$. Eggs deposited on the cage, pot, or on the label were not included in the analyses. To obtain sufficient replicates, four randomly chosen plants were used twice for $M$. brassicae, but oviposition preference was never tested on the same combination of plants.

Larval Preference For P. rapae as well as for M. brassicae, we used plants from EL44 and EL13 half sibs (one plant per chemotype per half-sib family and per herbivore). Two $0.9 \mathrm{~cm}$ diameter discs of each chemotype were cut from fully expanded leaves and placed in a circle (in an alternated design) in a $12 \mathrm{~cm}$ diameter Petri dish. We tested neonate larvae and 5-day-old larvae, which, until use, were feeding on Brassica oleracea var. gemnifera L., cultivar Cyrus leaves. The larvae were released individually at the center of the Petri dish with equal distance to all leaf discs $(N=20$ per species per age). After $4 \mathrm{~h}$, the amount of leaf material consumed was recorded visually and categorized as follows: $0=$ no damage, $1=$ only consumption of the lower leaf layers, $2=$ less then $10 \%$ was consumed, $3=$ between $10 \%$ and $50 \%$ of the leaf disc was consumed, and $4=$ more than $50 \%$ was consumed. We were not able to assign consumption categories in the experiment with neonates because they caused so little damage, but 5-day-old larvae showed distinct feeding patterns.

Larval Performance Larval performance was tested by forcing neonate larvae to stay on selected plants and measuring larval biomass and survival every other day. We selected forty 6-week-old plants (20 EL44 half sibs and 20 EL13 half sibs; 10 of each chemotype per half-sib family). To obtain a total of 80 plants, every plant was multiplied by cutting it into two halves and growing each plant in fresh pots. After 3 weeks, the plants were used to test performance of $M$. brassicae. Larvae were kept on the plant using $25 \mathrm{~mm}$ diameter meshed clip cages. After 4 days, these clip cages were replaced by $55 \mathrm{~mm}$ diameter meshed clip cages. After 8 days, M. brassicae larvae had consumed such large amounts of leaf tissue that the experiment had to be stopped. The remaining larvae were removed and weighed. All plants were clipped and after 3 weeks of regrowth used to asses performance of Pieris in the same way as we did for $M$. brassicae. However, $P$. rapae larvae were kept on the plants till day 18 when most larvae had pupated. Until day 4, each larva was feeding on a single leaf that we harvested to measure the consumed leaf area and sugar, glucosinolate, and amino acid content. These samples were considered to provide an estimate for the chemotype differences over the first 8 days of feeding.
The long-term performance of $M$. brassicae larvae was studied in a second experiment, in which three neonate larvae were placed on one plant (15 BAR and 15 NAS-type plants of EL 13). The larvae could freely move on the plant, but could not move to other plants due to a plastic cylinder and a water barrier around each plant. After 8 and 13 days, we determined larval mass and the number of dead or lost larvae. After 13 days on BAR-type plants, all but five larvae had died or were lost, so that we stopped the experiment. As dead larvae had often dried out, we excluded their biomass from all calculations.

Statistical Analysis In the oviposition preference experiments, total egg load may differ among individuals. Therefore, the number of eggs on each chemotype per individual female was treated as a paired sample. Per paired sample, we considered the chemotype with the highest egg load as the preferred type. Overall preference was tested with a Sign test. The number of eggs per plant and number of clusters per plant were not normally distributed, and were analyzed with the Wilcoxon matched-pair signed-ranks test. As there were no paired observations for cluster size, these data were analyzed with the Mann-Whitney $U$ test.

To analyze larval preference, we compared the average food consumption category between the two chemotypes by using the Wilcoxon matched-pair signed-ranks test.

In the larval performance experiments, the larval masses were not normally distributed and therefore analyzed for differences between the chemotypes with separate MannWhitney $U$ tests for each day followed by Bonferroni correction for multiple comparisons (for $M$. brassicae $\alpha=$ $0.05 / 4=0.0125$; for $P$. rapae $\alpha=0.05 / 8=0.0062$ ). Data on the leaf consumption of each herbivore on the two chemotypes were also tested with the Mann-Whitney $U$ test. The relationships between larval biomass and leaf consumption and between larval biomass and total glucosinolate concentration were tested by using Pearson product-moment correlations. The data were log-transformed to get a normal distribution. Before analysis of variance (ANOVA) total glucosinolate, sugar, and amino acid content data were logtransformed to meet the assumptions of ANOVA. Statistical analyses were performed with STATISTICA (data analysis software system), version 7.1. (StatSoft (2005); http://www. statsoft.com).

\section{Results}

Oviposition Preference Generalist and specialist adult herbivores did not prefer one chemotype over the other. Of the $68 \mathrm{M}$. brassicae females tested, 33.8\% oviposited on the plants, $47.1 \%$ preferred to oviposit on the cage, whereas 
$19.1 \%$ did not oviposit at all within 1 week. The chemotypes did not receive significantly different numbers of eggs (Table 1). M. brassicae, which is a gregarious species, deposited a total of 19 clusters on BAR-type and 19 on NAS-type plants. The number of clusters per plant and the average cluster size, ranging from 6 to 465 eggs per cluster, were not significantly different between chemotypes (Table 1).

Of the 35 P. rapae pairs tested, 32 females oviposited on plants, two females did not oviposit at all, and one female died. With an average of $53.5 \pm 5.1$ eggs per female, $61 \%$ deposited most eggs on NAS-type plants, and one deposited an equal amount of eggs on both chemotypes. The average numbers of eggs deposited on each chemotype did not significantly differ between chemotypes (Table 1). In total, BAR-type plants received 861 eggs and NAS-type plants 850 (Table 1).

Larval Preference Of the 20 5-day-old M. Brassicae larvae tested, only one preferred to feed on BAR-type leaf discs, whereas 19 preferred the NAS-type (Sign test: $Z=3.67, P<$ 0.001 ). This preference for NAS-type leaf discs was confirmed when corrected for the consumed quantity (feeding categories). M. brassicae larvae consumed more from NAS-type leaf discs than from BAR-type (Fig. 1; Wilcoxon matched-pairs test on feeding categories: $M$. brassicae $N=20, Z=3.743, P<0.001$ ). In contrast, the 20 5-day-old $P$. rapae larvae did not show a significant preference. Five larvae preferred NAS-type, 11 BAR-type, and four consumed from BAR-type as well as NAS-type leaf discs (Sign test: $Z=1.25, P=0.211$ ). Although $P$. rapae larvae consumed more from BAR-type leaves, the difference in feeding categories was not significant (Fig. 1; Wilcoxon matched-pairs test on feeding categories: $P$. rapae $N=20, Z=1.629, P=0.103)$. Consequently, we found no significant preference of $P$. rapae larvae for either chemotype.

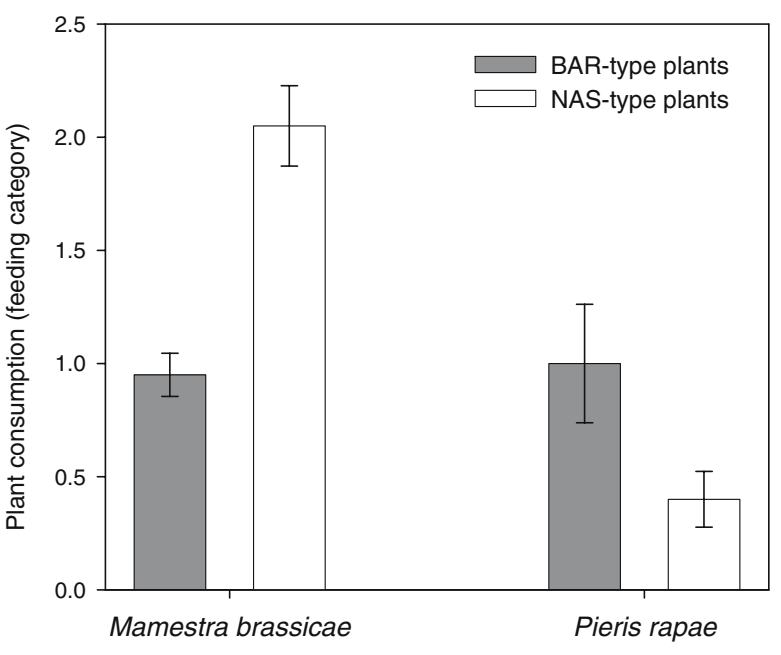

Fig. 1 Consumption of BAR-type (grey bars) and NAS-type (white bars) leaf discs by 5-day-old larvae of Mamestra brasscicae and Pieris rapae (feeding category averaged per Petri dish $\pm \mathrm{SE}$ )

Larval Performance and Chemotypes Over the first 8 days, the larval biomass accumulation of the generalist $M$. brassicae was affected by chemotype (Mann-Whitney $U$ test: $P<0.001$ for each day of recording). When forced to stay on NAS-type plants, $M$. brassicae larvae grew exponentially (Fig. 2a). On BAR-type plants, however, $M$. brassicae larvae hardly increased in biomass and were moribund. This difference in performance was positively correlated to the difference in leaf consumption after 4 days of feeding (correlation analysis: $r=0.942, r^{2}=0.887, P<$ 0.01). Consequently, $M$. brassicae larvae caused more damage to NAS-type leaves than to BAR-type (Fig. 3a; Mann-Whitney $U$ test: $U=12, Z=-7.583, P<0.001)$. Larval survival after 8 days on the plants was in line with these results. On NAS-type plants, all larvae were still alive, whereas on BAR-type plants $37.5 \%$ of the M. brassicae larvae had died. The results of the second experiment, in which the larvae could move freely on the plants, confirmed the results of the clip cage experiment. After 13 days, $89 \% \pm 10$ of the larvae had stayed and survived on

Table 1 Oviposition of Mamestra brassicae and Pieris rapae on BAR-type and NAS-type Barbarea vulgaris

\begin{tabular}{|c|c|c|c|c|c|c|c|c|}
\hline & \multicolumn{4}{|c|}{ Mamestra brassicae } & \multicolumn{4}{|c|}{ Pieris rapae } \\
\hline & BAR & NAS & $P$ & $\mathrm{Z}$ & BAR & NAS & $P$ & $Z$ \\
\hline Preference $^{\mathrm{a}}$ & 14 & 11 & 0.838 & 0.204 & 12 & 19 & 0.472 & 0.720 \\
\hline $\operatorname{Eggs}^{\mathrm{b}}$ & $220 \pm 40.9$ & $193 \pm 51.7$ & 0.399 & 0.843 & $26.9 \pm 18.2$ & $26.6 \pm 14.5$ & 0.922 & 0.100 \\
\hline Clusters/plant ${ }^{\mathrm{c}}$ & $1.36 \pm 0.2$ & $1.73 \pm 0.3$ & 0.951 & 0.061 & & & & \\
\hline Cluster size $^{\mathrm{d}}$ & $162 \pm 23.4$ & $112 \pm 32.9$ & 0.800 & 0.254 & & & & \\
\hline
\end{tabular}

\footnotetext{
${ }^{a}$ Times when that chemotype received most eggs in a pairwise comparison

${ }^{\mathrm{b}}$ Average number of eggs per plant $\pm \mathrm{SE}$

${ }^{\mathrm{c}}$ Average number of clusters per plant $\pm \mathrm{SE}$

${ }^{\mathrm{d}}$ Average number of eggs per cluster $\pm \mathrm{SE}$
} 

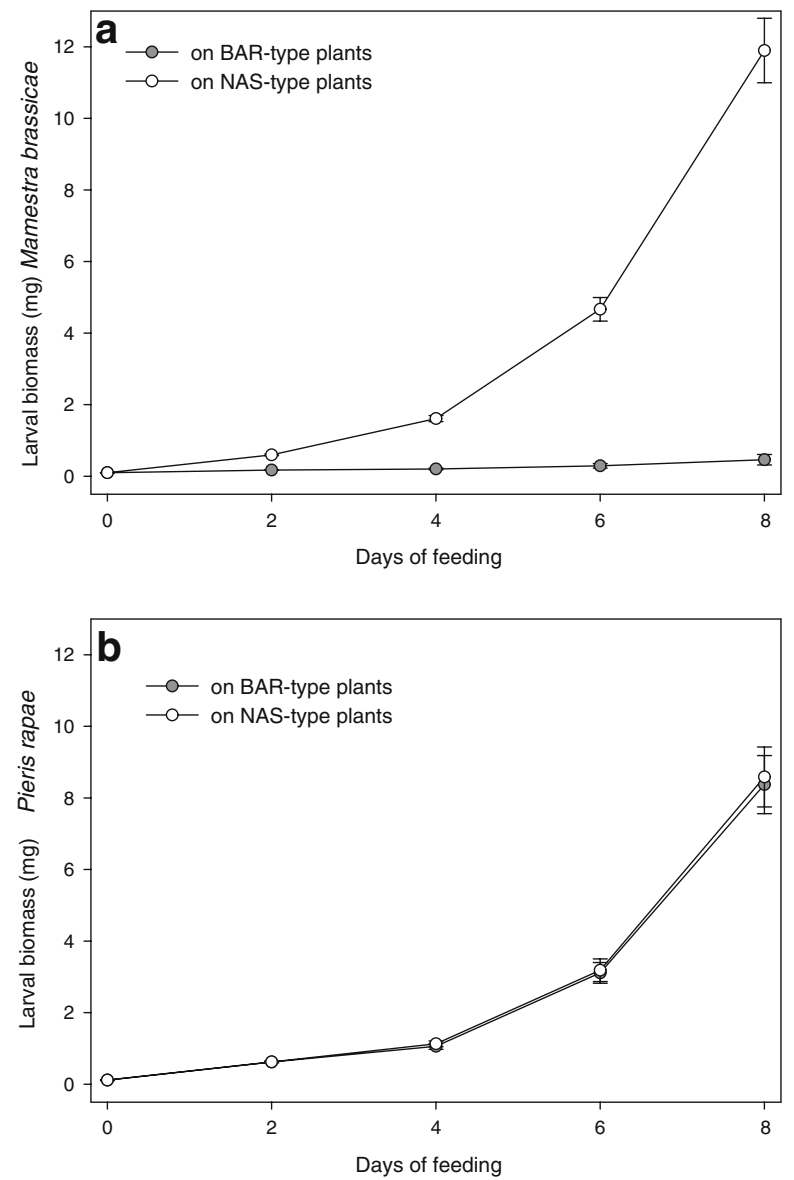

Fig. 2 Biomass accumulation of a Mamestra brassicae and $\mathbf{b}$ Pieris rapae larvae during 8 days of feeding BAR-type (grey bars) and NAS-type (white bars) Barbarea vulgaris plants \pm SE

NAS-type plants and weighed $42.13 \pm 2.69 \mathrm{mg}$, whereas only $20 \% \pm 10$ of the larvae had stayed and survived on BAR-type plants and weighed only $4.11 \pm 0.02 \mathrm{mg}$.

In contrast to $M$. brassicae larvae, $P$. rapae larvae grew and survived equally well on both chemotypes. P. rapae larval biomass accumulation over time showed no significant difference between chemotypes over the first 18 days (Fig. 2b; Mann-Whitney $U$ test: $P>0.05$ for each day of recording) and was positively correlated to leaf consumption after 4 days (correlation: $r=0.768, r^{2}=0.589, P<0.01$ ). Leaf damage due to $P$. rapae feeding was not different between the chemotypes (Fig. 3b; Mann-Whitney $U$ test: $U=673, Z=-1.217, P=0.223)$. After 8 days, larval mortality was $7.5 \%$ on NAS-type and $12.5 \%$ on BAR-type plants. On day 14, the first P. rapae larvae started pupating. After 16 days on BAR-type plants, $45 \%$ had pupated, and on NAS-type plants this was $47.5 \%$. At the end of the experiment, after 18 days, larval weights were still not significantly different on the chemotypes (on BAR-type: $161.9 \pm 7.37 \mathrm{mg}$, on NAS-type: $175.24 \pm 5.63 \mathrm{mg}$; MannWhitney $U$ test: $U=238, Z=-1.131, P=0.265$ ).
Larval Performance and Total Glucosinolate Content The leaves on which larvae were feeding differed in glucosinolate composition (glucobarbarin vs. gluconasturtiin) and in total glucosinolate content (Fig. 3c,d). In both chemotypes, we detected glucobarbarin, gluconasturtiin, glucosibarin, glucobrassicin, 4-methoxyglucobrassicin, and neoglucobrassicin. In both families, BAR-type leaves had on average 1.5 times higher total glucosinolate levels than NAS-type leaves (Fig. 3c; ANOVA type effect: $F_{1,143}=22.831, P<0.001$ ). Because $M$. brassicae fed more on NAS plants, overall a negative - but weak - correlation of total glucosinolate content with the consumed leaf area was observed (correlation: $r$ $\left.(X, Y)=-0.26, r^{2}=0.065, P<0.05\right)$. To analyze in more detail whether total glucosinolate level determines larval consumption and performance, we also examined the correlation within each chemotype. Within chemotypes, the range of glucosinolate concentrations was substantial (factor 6-7), but there was no negative correlation between glucosinolate level and larval biomass (Fig. 4; Correlation: within BAR, $r(X, Y)=$ $0.15, r^{2}=0.024, P=0.932$; within NAS, $r(X, Y)=0.28, r^{2}=$ $0.078, P=0.090)$. Moreover, larvae on BAR-type leaves with similar low levels of glucosinolates as NAS-types consumed and performed considerably worse (Fig. 4; glucosinolate levels $<35 \mu \mathrm{mol} \mathrm{g}^{-1}$ dry mass). There was also no difference in total glucosinolate level from BAR-type leaves on which the larvae survived or died (with living larvae: $31.32 \pm$ $2.95 \mu \mathrm{mol} \mathrm{g}{ }^{-1}$, with dead larvae: $32.81 \pm 6.49 \mu \mathrm{mol} \mathrm{g}{ }^{-1}$; ANOVA: $F_{1,29}=0.059, P>0.05$; Fig. 4 ). As the performance of $P$. rapae larvae was similar among chemotypes and families, there was no correlation of larval biomass with total glucosinolate level.

Larval Performance and Nutritional Value Total sugar content of both chemotypes was composed of five consistently detected sugars, which were glucose, sucrose, sorbitol, fructose, and trehalose (from high to low average concentration). Total amino acid content of both chemotypes was composed of 11 consistently detected amino acids, which were threonine, isoleucine, arginine, serine, glutamate, aspartate, glutamine, asparagine, phenylalanine, tyrosine, and histidine (from high to low average concentration). Because the individual sugars and amino acids showed effects similar to the total levels (results not shown), we only present data on total levels.

In contrast to the total glucosinolate level, sugar and amino acid content did not differ between the chemotypes (Fig. 3e-h). Although in the M. brassicae experiment the total sugar content was overall higher in BAR-type plants, there was a significant interaction between chemotype and family (Fig. 3e; ANOVA type effect: $F_{1,75}=12.014, P<$ 0.001 ; type $\times$ family $F_{1,75}=10.252, P<0.05$ ). Similar interactions between chemotype and family were shown for amino acid content of the plants in the M. brassicae 
Fig. 3 Leaf characteristics after 4 days of larval feeding of Mamestra brassicae (left graphs) or Pieris rapae (right graphs) on Barbarea vulgaris \pm SEM: a and $\mathbf{b}$ consumed leaf area $\left(\mathrm{cm}^{2}\right)$, $\mathbf{c}$ and $\mathbf{d}$ total glucosinolate content, $\mathbf{e}$ and $\mathbf{f}$ total sugar content, $\mathbf{g}$ and $\mathbf{h}$ total amino acid content. Results are depicted per chemotype (grey bars BAR-type plants; white bars NAS-type plants) and per half-sib family (no hatching EL13, hatching EL44)
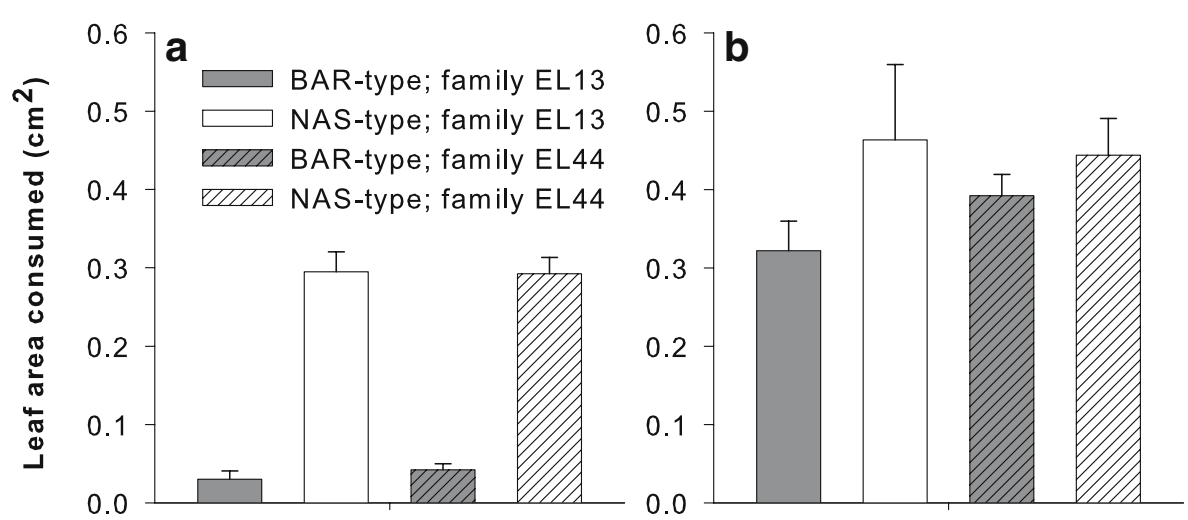

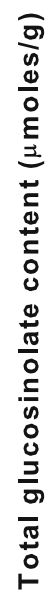
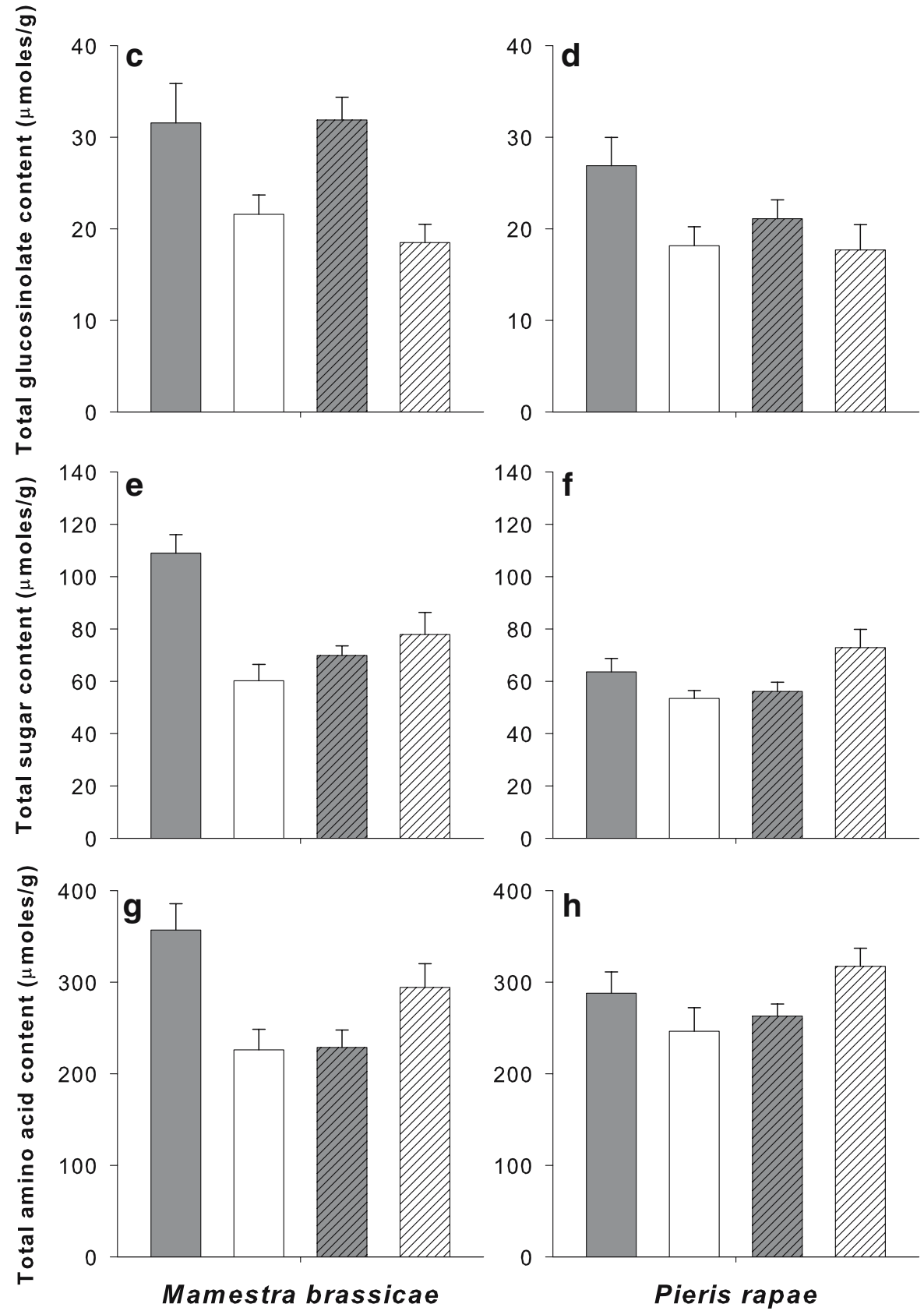


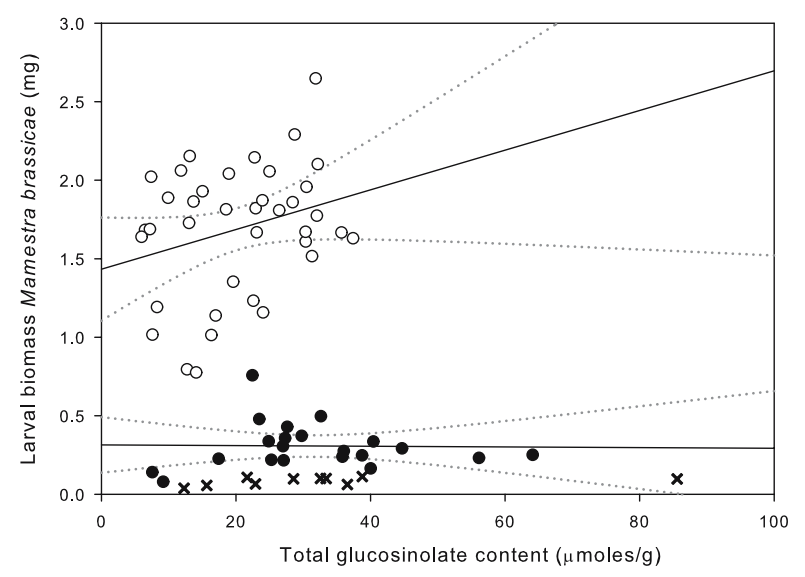

Fig. 4 Correlation of total glucosinolate content and the larval biomass after 4 days feeding of Mamestra brassicae experiment on NAS-type (white dots), BAR-type (black dots), and dead larvae of on BAR-type (black crosses) Barbarea vulgaris plants with their correlations per chemotype (black line) and their 95\% confidence intervals (dotted lines)

experiment and for sugars and amino acid content of plants in the $P$. rapae experiment. In all chemotype $\times$ family interactions, the BAR-type of the EL13 half-sib family had higher levels of primary metabolites than the NAS-type of that family (Fig. 3e-h). In the EL44 half-sib family, the sugar and amino acid level differences of the chemotypes were negligible in plants during the $M$. brassicae experiment or even opposite to those of the EL13 during the P. rapae experiment. As sugar and amino acid content did not vary consistently with chemotype, these cannot explain the differences in larval performance and preference between the chemotypes.

\section{Discussion}

NAS and BAR chemotypes of B. vulgaris differentially affected preference and performance of the generalist herbivore $M$. brassicae but not the specialist $P$. rapae. Larvae of M. brassicae grew exponentially and had $100 \%$ survival on NAS-type leaves, but hardly grew and had a high mortality when feeding on BAR-type plants. As the dose-dependent effect of total glucosinolate content on herbivores is well-known (Li et al. 2000; Agrawal and Kurashige 2003; Mewis et al. 2006), the poor performance of $M$. brassicae could have been caused by the on average 1.5 times higher total glucosinolate content of BAR-type plants compared to NAS-type plants (Van Leur et al. 2006). However, we did not observe any dose-dependent effect within the chemotypes. Moreover, M. brassicae larvae on BAR-type plants with total glucosinolate levels similar to NAS-type plants still performed significantly worse. Hence, we exclude total glucosinolate level as explanatory factor for the differences found between chemotypes on larval biomass and leaf consumption.

In addition to total glucosinolate content, sugar and amino acid contents differed between chemotypes, but the pattern was inconsistent among half-sib families. The statistical interaction between chemotype and family found for sugar and amino acid levels was not found for herbivore performance and preference (Fig. 3). Therefore, total sugar content and total amino acid content can not explain the observed effects on $M$. brassicae.

In a different $B$. vulgaris polymorphism, described by Agerbirk et al. (2003b), there were P- and G-type plants that differed in resistance to Plutella xylostella. Other than our BAR/NAS polymorphism, the P-type and G-types also differed in trichome density, did not co-occur in natural populations, were hard to cross, and neither of the Danish types had a high content of gluconasturtiin in the leaves (Agerbirk, personal communication).The resistance of the G-type to $P$. xylostella was due to a difference in saponin content (Agerbirk et al. 2003a). Based on these findings, we compared saponin levels between BAR and NAS-type plants by using LC-TOF-MS (see supplemental data). This analysis revealed that the levels of the saponin described by Agerbirk et al. (2003a) and a saponin described by Shinoda et al. (2002) did not differ between the NAS and BAR chemotypes (supplemental data). Therefore, we exclude these saponins as an explanatory factor for the poor performance of $M$. brassicae on BAR-type plants.

The observed effects are likely caused by difference in glucosinolate structures and their break-down products. BAR-type plants were more toxic and deterrent to $M$. brassicae than the NAS-type plants. This suggests that M. brassicae can deal effectively with gluconasturtiin and isothiocyanates, but not with glucobarbarin and resulting oxazolidine-2-thiones. The latter compounds have received hardly any attention in chemical-ecological literature. Generalist herbivores possess broad-spectrum detoxification enzymes such as P450 enzymes and mixed-function oxidases (MFO) that enable them to deal with a wide range of allelochemicals, including glucosinolates (Schoonhoven et al. 1998; Li et al. 2000). Which detoxification mechanism is present in $M$. brassicae and why it can handle the presumably more toxic isothiocyanates, but not the oxazolidine thiones is unknown. The non-different performance of $P$. rapae on the chemotypes may indicate that NSP enzymes are equally effective in redirecting the hydrolysis pathways of both chemotypes towards the generally less toxic nitriles (Wittstock et al. 2004). Identification of the bioactive compounds could be acquired by using bioassayguided fractionation.

Neither herbivore species significantly preferred one of the chemotypes as a host plant for oviposition. Even though isothiocyanates are known to elicit anemotaxis in herbi- 
vores at extremely low concentrations (Finch and Skinner 1982), the concentrations of volatile cues emitted by our undamaged plants may have been below the detection limit (Finch et al. 1978). Upon damage or induction by herbivores, volatile levels may rise and affect oviposition preference (Rothschild and Schoonhoven 1977; Bruinsma et al. 2007). Next to chemical suitability, the surface on which to oviposit can be an important factor (Renwick and Chew 1994). In our experiment, however, leaf surface structure was unlikely to affect oviposition preference between chemotypes because the chemotypes did not have apparent differences in leaf surface (e.g., trichomes) in contrast to the completely different $B$. vulgaris polymorphism reported by Agerbirk et al. (2003b).

As M. brassicae larvae performed poorly on BAR-type plants, the lack of oviposition preference of adults seems to be non-adaptive. The discrepancy between larval performance and oviposition preference on $B$. vulgaris has also been shown for the Diamondback moth (Plutella xylostella) (Serizawa et al. 2001; Badenes-Perez et al. 2006). It may occur when insects or plants are new to an area and there has not been enough time for evolutionary adaptation (Agosta 2006). Whether this is the case for M. brassicae and the B. vulgaris chemotypes is unknown.

Co-evolutionary theory suggests that the variation of plant defense compounds is maintained by sequential adaptations of specialist herbivores and plants (Agrawal et al. 1999; Cornell and Hawkins 2003). The good performance of $P$. rapae on both chemotypes suggests that neither chemotype is effectively defended against this specialist. On the contrary, BAR-type plants are defended against the generalist M. brassicae. Although we have no experimental evidence indicating which chemotype is the newest form, the effective defense of BAR-type plants against $M$. brassicae suggests an evolutionary adaptive step in which BAR-type evolved from NAS-type. This matches with the biosynthetic origin of these glucosinolates. Gluconasturtiin is presumably the precursor that is hydroxylated to produce glucobarbarin. Moreover, gluconasturtiin occurs in five times more genera than glucobarbarin (Fahey et al. 2001). This does not preclude, however, that the NAS-types found locally in the Netherlands are due to a loss-of-function mutation from the BARtype. In natural populations of B. vulgaris, there are only 0-22\% NAS-type plants (Van Leur et al. 2006). This results in a potentially limited genetic basis for NAS-type plants compared to BAR-type plants, which could contribute to linkage disequilibrium between the BAR/NAS locus and other loci (for instance closely linked loci). However, the natural population from which we selected seed batches for these experiments had a phenotype frequency close to a Hardy-Weinberg equilibrium (22\% potential NAS-type fathers observed instead of $25 \%$ expected). We estimate the chance of linkage disequilibrium effects in our experiments to be relatively small. Additionally, there are no $a$ priori indications of closely linked loci that affect herbivore performance.

For the plant, the benefit of increasing its defense against $M$. brassicae will be larger than increasing its defense against $P$. rapae. Being gregarious and larger, $M$. brassicae larvae are more harmful to the chosen individual (many larvae feeding from one plant) and will more strongly reduce plant fitness than the solitary P. rapae (only one or few larvae feeding on a plant). Therefore, irrespective of the degree of specialization of the herbivores, it will be more important for $B$. vulgaris to be defended against $M$. brassicae than against $P$. rapae.

Based on our results, we would expect BAR-type plants in the field to suffer less from herbivory than NAS-type plants. Besides being the chemotype that is most severely damaged by $M$. brassicae larvae, the NAS chemotype is also the recessive genotype. Therefore, if herbivorous insects are the only selective force, we expect that natural selection will drive natural populations towards $100 \%$ BAR-types. European populations of B. vulgaris indeed are mainly dominated by BAR-type plants, but a minority number of populations has still up to $22 \%$ NAS-type plants. This indicates that in these populations there may be other factors that play a role in maintaining this chemical polymorphism. Other factors that may differ between the two types and that determine plant fitness, e.g., belowground herbivory, higher trophic level interactions, and inter- and intraspecific competition, need to be included in future studies.

Acknowledgements We thank Leo Koopman from Entomology WUR for culturing and providing insects, Ciska Raaijmakers and Sylvia Lenting for technical assistance with the chemical analysis, and Freddy ten Hooven, Mariëlle Oomen, and Sander Meijer for practical assistance with several experiments. This research was supported by an ALW grant no.813.04.005, and a VIDI grant, no. 864.02.001, of the Netherlands Organisation for Scientific Research (NWO). Publication 4239 NIOO-KNAW Netherlands Institute of Ecology.

Open Access This article is distributed under the terms of the Creative Commons Attribution Noncommercial License which permits any noncommercial use, distribution, and reproduction in any medium, provided the original author(s) and source are credited.

\section{References}

Agerbirk, N., Olsen, C. E., Bibby, B. M., Frandsen, H. O., Brown, L. D., Nielsen, J. K., and ENwiCK, J. A. A. 2003a. A saponin correlated with variable resistance of Barbarea vulgaris to the diamondback moth Plutella xylostella. J. Chem. Ecol. 29:1417-1433.

Agerbirk, N., OrgaArd, M., and Nielsen, J. K. 2003b. Glucosinolates, flea beetle resistance, and leaf pubescence as taxonomic 
characters in the genus Barbarea (Brassicaceae). Phytochemistry 63:69-80.

Agerbirk, N., Petersen, B. L., Olsen, C. E., Halkier, B. A., and NIELSEN, J. K. 2001. 1,4-Dimethoxyglucobrassicin in Barbarea and 4-hydroxyglucobrassicin in Arabidopsis and Brassica. J. Agric. Food Chem. 49:1502-1507.

AGosta, S. J. 2006. On ecological fitting, plant-insect associations, herbivore host shifts, and host plant selection. Oikos 114:556-565.

Agrawal, A. A., Gorski, P. M., and Tallamy, D. W. 1999. Polymorphism in plant defense against herbivory: Constitutive and induced resistance in Cucumis sativus. J. Chem. Ecol. 25:2285-2304.

Agrawal, A. A., and Kurashige, N. S. 2003. A role for isothiocyanates in plant resistance against the specialist herbivore Pieris rapae. J. Chem. Ecol. 29:1403-1415.

AKHTAR, Y., and ISMAN, M. B. 2003. Larval exposure to oviposition deterrents alters subsequent oviposition behavior in generalist, Trichoplusia $n i$ and specialist, Plutella xylostella moths. J. Chem. Ecol. 29:1853-1870.

Badenes-Perez, F. R., Nault, B. A., and Shelton, A. M. 2006. Dynamics of Diamondback moth oviposition in the presence of a highly preferred non-suitable host. Entomol. Exp. Appl. 120:23-31.

BERENBAUM, M. R. 1995. Turnabout is fair play-Secondary roles for primary compounds. J. Chem. Ecol. 21:925-940.

Borek, V., Elberson, L. R., Mccaffrey, J. P., and Morra, M. J. 1998. Toxicity of isothiocyanates produced by glucosinolates in Brassicaceae species to black vine weevil eggs. J. Agric. Food Chem. 90:109-112.

BRUINSMA, M., VAN, DAM, N. M., VAN, LOON, J. J. A., and DiCKE, M. 2007. Jasmonic acid-induced changes in Brassica oleracea affect oviposition preference of two specialist herbivores. J. Chem. Ecol. 33:655-668.

BUCHNER, R. 1987. Approach to determination of HPLC response factors for glucosinolates, pp. 50-58, in J. P. Wathelet (ed.). Glucosinolates in RapeseedMartinus Nijhoff Publishers, Dordrecht, The Netherlands.

Burow, M., Markert, J., Gershenzon, J., and Wittstock, U. 2006. Comparative biochemical characterization of nitrile-forming proteins from plants and insects that alter myrosinase-catalysed hydrolysis of glucosinolates. FEBS J. 273:2432-2446.

Canistro, D., Della, Croce, C., Iori, R., Barillari, J., Bronzetti, G., Poi, G., Cini, M., Caltavuturo, L., Perocco, P., and Paolini, M. 2004. Genetic and metabolic effects of gluconasturtiin, a glucosinolate derived from cruciferae. Mutat. Res. 545:23-35.

CHEW, F. S. 1988. Biological effects of glucosinolates, pp. 155-181, in H. G. Cutler (ed.). Biologically Active Natural ProductsACS, Washington DC.

Cornell, H. V., and Hawkins, B. A. 2003. Herbivore responses to plant secondary compounds: A test of phytochemical coevolution theory. Am. Nat. 161:507-522.

EC. 1990. Oil seeds - Determination of glucosinolates High Performance Liquid Chromatography. Official Journal of the European Communities L 170/28. Annex VIII:03.07.27-34.

FAHEY, J. W., ZALCMANN, A. T., and TALALAY, P. 2001. The chemical diversity and distribution of glucosinolates and isothiocyanates among plants. Phytochemistry 56:5-51.

Finch, S., and KiENEGGER, M. 1997. A behavioural study to help clarify how undersowing with clover affects host-plant selection by pest insects of brassica crops. Entomol. Exp. Appl. V84:165-172.

FincH, S., and SKINNER, G. 1982. Trapping cabbage root flies in traps baited with plant extracts and with natural and synthetic isohiocyanates. Entomol. Exp. Appl. 31:133-139.

Finch, S., SkINNER, G., and FreEman, G. M. 1978. Distribution and analysis of cabbage root fly pupal populations. Ann. Appl. Biol. $88: 351-356$
HANKO, V. P., and OHRER, J. S. 2004. Determination of amino acids in cell culture and fermentation broth media using anion-exchange chromatography with integrated pulsed amperometric detection. Anal. Biochem. 324:29-38.

HUANG, X., and ENWICK, J. A. A. 1994. Relative activities of glucosinolates as oviposition stimulants for Pieris rapae and $P$. napi oleracea. J. Chem. Ecol. 20:1025-1037.

Huang, X. P., ENwick, J. A. A., and Sachdevgupta, K. 1994a. Oviposition stimulants in Barbarea-Vulgaris for Pieris-Rapae and P-Napi-Oleracea-Isolation, identification and differential activity. J. Chem. Ecol. 20:423-438.

Huang, X. P., ENwick, J. A. A., and Sachdevgupta, K. 1994 b. Oviposition Stimulants in Barbarea vulgaris for Pieris rapae and P. napi Oleracea-Isolation, identification and differential activity. J. Chem. Ecol. 20:423-438.

Kerfoot, W. C., Newman, R. M., and HAnscom, Z. 1998. Snail reaction to watercress leaf tissues: reinterpretation of a mutualistic 'alarm' hypothesis. Freshw. Biol. 40:201-213.

KJAER, A., and GMELIN, R. 1957. Isothiocyanates 28. A new isothiocyanate glucoside (glucobarbarin) furnishing (-)-5-phenyl2-oxazolidinethione upon enzymic hydrolysis. Acta Chem. Scand. 11:906-907.

Kroymann, J., TeXtor, S., ToKUhisa, J. G., FALK, K. L., Bartram, S., Gershenzon, J., and Mitchell-Olds, T. 2001. A gene controlling variation in Arabidopsis glucosinolate composition is part of the methionine chain elongation pathway. Plant Physiol. (Rockv) 127:1077-1088.

Lambrix, V., EIChelt, M., Mitchell-Olds, T., Kliebenstein, D. J., and Gershenzon, J. 2001. The Arabidopsis epithiospecifier protein promotes the hydrolysis of glucosinolates to nitriles and influences Trichoplusia ni herbivory. Plant Cell 13: 2793-2807.

Lazzeri, L., Curto, G., Leoni, O., and Dallavalle, E. 2004. Effects of glucosinolates and their enzymatic hydrolysis products via myrosinase on the root-knot nematode Meloidogyne incognita (Kofoid et White) Chitw. J. Agric. Food Chem. 52:6703-6707.

Li, Q., Eigenbrode, S. D., Stringam, G. R., and Thiagarajah, M. R. 2000. Feeding and growth of Plutella xylostella and Spodoptera eridania on Brassica juncea with varying glucosinolate concentrations and myrosinase activities. J. Chem. Ecol. 26:2401-2419.

Lichtenstein, E. P., Strong, F. M., and Morgan, D. G. 1962. Identification of 2-phenylethylisothiocyanate as an insecticide occurring naturally in the edible parts of turnips. J. Agric. Food Chem. 10:30-33.

LoudA, S., and Mole, S. 1991. Glucosinolates: chemistry and ecology, pp. 123-164, in G. A. Rosenthal, and M. R. Berenbaum (eds.). Herbivores. Their interactions with secondary plant metabolites. Vol. 1Academic, San Diego, CA.

Ludwig-Müller, J., Bennett, R. N., Kiddle, G., Ihmig, S., UPPEL, M., and HilgenberG, W. 1999. The host range of Plasmodiophora brassicae and its relationship to endogenous glucosinolate content. New. Phytol. 141:443-458.

Mewis, I., ToKuhisA, J. G., Schultz, J. C., ApPel, H. M., Ulrichs, C., and GERSHENZON, J. 2006. Gene expression and glucosinolate accumulation in Arabidopsis thaliana in response to generalist and specialist herbivores of different feeding guilds and the role of defense signaling pathways. Phytochemistry 67:2450-2462.

Potter, M. J., Vanstone, V. A., Davies, K. A., Kirkegaard, J. A., and ATHJEN, A. J. 1999. Reduced susceptibility of Brassica napus to Pratylenchus neglectus in plants with elevated root levels of 2-phenylethyl glucosinolate. J. Nematol. 31:291-298.

Potter, M. J., VAnStone, V. A., DaVies, K. A., and ATHJEN, A. J. 2000. Breeding to increase the concentration of 2-phenylethyl glucosinolate in the roots of Brassica napus. J. Chem. Ecol. 26:1811-1820. 
Ratzka, A., Vogel, H., Kliebenstein, D. J., Mitchell-Olds, T., and KroymanN, J. 2002. Disarming the mustard oil bomb. Proc. Natl. Acad. Sci. U S A 99:11223-11228.

Reichelt, M., Brown, P. D., Schneider, B., Oldham, N. J., Stauber, E., Tokuhisa, J., Kliebenstein, D. J., MitchellOLDS, T., and GERSHENZON, J. 2002. Benzoic acid glucosinolate esters and other glucosinolates from Arabidopsis thaliana. Phytochemistry 59:663-671.

RenwiCK, J. A. A., and CHEW, F. S. 1994. Oviposition behavior in lepidoptera. Annu. Rev. Entomol. 39:377-400.

RENwick, J. A. A., ADKE, C. D., SACHDEV-Gupta, K., and STÄDler, E. 1992. Leaf surface chemicals stimulating oviposition by Pieris rapae (Lepidoptera: Pieridae) on cabbage. Chemoecology 3:33-38.

ROJAS, J. C. 1999. Influence of host plant damage on the host-finding behavior of Mamestra brassicae (Lepidoptera: Noctuidae). Environ. Entomol. 28:588-593.

Rojas, J. C., Wyatt, T. D., and BIRCh, M. C. 2000. Flight and oviposition behavior toward different host plant species by the cabbage moth, Mamestra brassicae (L.) (Lepidoptera: Noctuidae). J. Insect Behav. 13:247-254.

RothSCHILD, M., and SCHOONHOVEN, L. M. 1977. Assessment of egg load by Pieris brassicae (Lepidoptera: Pieridae). Nature 266:352-355.

Sang, J. P., Minchinton, I. R., Johnstone, P. K., and Truscott, R. J. W. 1984. Glucosinolate profiles in the seed, root and leaf tissue of cabbage, mustard, rape seed, radish and swede. Can. J. Plant. Sci. 64:77-93.

SARWAR, M., and KIRKEGAARD, J. A. 1998. Biofumigation potential of brassicas-II. Effect of environment and ontogeny on glucosinolate production and implications for screening. Plant Soil 201:91-101.

Schoonhoven, L. M., Jermy, T., and Van, LoON, J. J. A. 1998. Insect-Plant Biology. From physiology to evolution. Chapman \& Hall, London.

SERIZAWA, H., ShINODA, T., and KaWAI, A. 2001. Occurrence of a feeding deterrent in Barbarea vulgaris (Brassicales: Brassicaceae), a crucifer unacceptable to the diamondback moth, Plutella xylostella (Lepidoptera: Plutellidae). Appl. Entomol. Zool. 36:465-470.

Serra, B., osa, E., Iori, R., Barillari, J., Cardoso, A., Abreu, C., and OLLIN, P. 2002. In vitro activity of 2-phenylethyl glucosinolate, and its hydrolysis derivatives on the root-knot nematode Globodera rostochiensis (Woll.). Sci. Hortic. (Amst) 92:75-81.
Shinoda, T., NagaO, T., NAKayAma, M., SerizaWA, H., KoShiOKA, M., OKABE, H., and KAWAI, A. 2002. Identification of a triterpenoid saponin from a crucifer, Barbarea vulgaris, as a feeding deterrent to the diamondback moth, Plutella xylostella. J. Chem. Ecol. 28:587-599.

SiMPSON, S. J., and SiMPSON, C. L. 1990. The Mechanisms of Nutritional Compensation by Phytophagous Insects, pp. 111160, in E. A. Bernays (ed.). Insect-Plant Interactions, vol. 2.CRC Press, Boca Raton, FL.

Theunissen, J., Ouden, H., and Wit, A. K. H. 1985. Feeding capacity of caterpillars on cabbage, a factor in crop loss assessment. Entomol. Exp. Appl. V39:255-260.

VAN, DAM, N. M., HADWICH, K., and BALDWIN, I. T. 2000. Induced responses in Nicotiana attenuata affect behavior and growth of the specialist herbivore Manduca sexta. Oecologia 122:371-379.

VAN, DAM, N. M., WITJES, L., and SvATOS, A. 2004. Interactions between aboveground and belowground induction of glucosinolates in two wild Brassica species. New Phytol. 161:801-810.

VAn, Leur, H., AaiJMakers, C. E., and Van, Dam, N. M. 2006. A heritable glucosinolate polymorphism within natural populations of Barbarea vulgaris. Phytochemistry 67:1214-1223.

Van, Loon, J. J. A., BlaAkmeer, A., Griepink, F. C., Van, Beek, T. A., Schoonhoven, L. M., and de, Groot, A. 1992. Leaf surface compound from Brassica oleracea (Cruciferae) induces oviposition by Pieris brassicae (Lepidoptera: Pieridae). Chemoecology 3:39-44.

WADLEIGH, R. W., and YU, S. J. 1988. Detoxification of isothiocyanate allelochemicals by glutathione transferase in three lepidopterous species. J. Chem. Ecol. 14:1279-1288.

WIECZOREK, H. 1976. The glycoside receptor of the larvae of Mamestra brassicae L. (Lepidoptera, Noctuidae). J. Comp. Physiol. A Sens. Neural Behav. Physiol. 106:153-176.

Wittstock, U., Agerbirk, N., Stauber, E. J., Olsen, C. E., HipPler, M., Mitchell-Olds, T., Gershenson, J., and Vogel, H. 2004. Successful herbivore attack due to metabolic diversion of a plant chemical defense. Proc. Natl. Acad. Sci. U S A 101: 4859-4864.

WitTstock, U., KLiebenstein, D. J., LAMBrix, V., EICHELT, M., and GERSHENZON, J. 2003. Glucosinolate hydrolysis and its impact on generalist and specialist insect herbivores, pp. 101-125, in J. T. Romeo (ed.). Recent Advances in Phytochemistry: Integrative Phytochemistry: From Ethnobotany to Molecular Ecology, vol. 37Pergamon Press, Oxford. 